\title{
DEVELOPING QUESTIONNAIRE FOR POST GRADUATE STUDIES IN CONSTRUCTION MANAGEMENT
}

\author{
Yakubu N. Sanda ${ }^{1 *}$; Natalia A. Anigbogu' ${ }^{2}$ Yohana D. Izam $^{3}$; Hannatu L. Datukun ${ }^{4}$ \\ ${ }^{1}$ Department of Estate Management, Faculty of Environmental Sciences, University of Jos, Nigeria \\ ${ }^{2 \& 3}$ Department of Building, Faculty of Environmental Sciences, University of Jos, Nigeria \\ ${ }^{4}$ Department of Estate Management, Faculty of Environmental Sciences, Plateau Polytechnic, Nigeria \\ E-mail: *sanda_yakubu@yahoo.com
}

\begin{abstract}
Although questionnaires are widely used in construction management studies, designing the instrument has proven to be a difficult task among research students. This article explored the process of developing and testing questionnaires for construction management studies focusing on managing risks in Public Private Partnership (PPP) housing projects. The processes of developing questionnaire were grouped into four stages consisting of the background, conceptualization, design and instrument testing and administration. Using the processes identified, a flowchart indicating step-by-step stages for developing questionnaires was designed. Results of validity and reliability tests conducted on certain aspects of the questionnaire indicated that the instrument can be relied upon to generate acceptable data for scientific research. The main contribution of this paper is expanding the scope and simplifying the design of questionnaire among upcoming researchers in the field of construction management. This study recommends the design for students undertaking construction management related studies.
\end{abstract}

Keywords: Developing, Questionnaire, Post graduate, Construction, Management.

\section{INTRODUCTION}

Over the years evolving complex and complicated societal problems have led to the emergence of varying research approaches as well as methods of data collection in order address those challenges. One of the widely accepted tools of data collection adopted in many fields including construction management is the questionnaire. The use of questionnaire as a valid tool of data collection among scholars in construction management has gained increased acceptance in recent years. Questionnaire has a well established track record in the field of construction management owing to its grounding in the positivist methodological mindset of the research community (Seymour and Rooke, 1995). In addition, the ever increasing emphasis on standardization of research instruments and evidence-based findings make a strong case for the adoption of questionnaire in construction management studies.

Questionnaire plays an important role in construction management research especially surveys. Questionnaires are used to collect information in a standardised manner on knowledge, attitudes opinions, behaviours, facts and other relevant data related to a study (Radhakrishna, 2007). In the field of construction management, questionnaire could be designed to obtain information from clients, contractors, consultants, consumers and other stakeholders that form the respondents in a particular study. For instance, the opinion of consultants could be sought on essential risks related to road construction projects, contractors could be probed on the causes of cost overruns in building projects, the attitudes of clients towards motivation of operatives on sites among others could also be explored using questionnaire and results from such surveys allows the generalization of findings to the wider population when gathered from a representative sample of a defined population, However, questionnaire can only produce valid and meaningful results if they are adequately designed and the questions are clear, precise and if they are asked consistently across all respondents (Mathers, Fox \& Hunn, 2009). The language of the questions, the type of questions used, the order in which they are arranged and many other details all impact the results of the research (Yaddanapudi and Yaddanapudi, 2019) In adopting questionnaire as a tool for data collection therefore, it is desirable that researchers pay adequate attention to the design process because when the 
instruments are poorly designed, they may not capture the essence of what the researcher is attempting to measure due to different types of measurement error (Artino, La Rochelle, Dezee \& Gehlbach, 2014).

Despite the widespread adoption of questionnaire in construction management and other related disciplines, literature has shown that these studies are biased towards general application of the instrument rather than its design. For instance, Bird (2009) reviewed 46 articles in which questionnaires were used in obtaining data and reported that only few explained the basic techniques employed for their development and implementation. Radhakrishma, Leite and Bagget (2003) reviewed 748 research studies and reported that, out of the $64 \%$ that used questionnaire, a third of these studies reviewed did not report the design process as well as the procedure for establishing validity and reliability of those instruments. Furthermore, while different disciplines have produced guides on questionnaire practices in relation to their own fields, there is little or no commentary regarding such research experiences in the construction industry which is characterised by complex challenges of varying degrees (Root and Blisma, 2003). In addition, literature in construction management has limited guidance on the best way to design and test the instrument; consequently, many researchers in the field fail to use best practices in designing questionnaires. As a result, the reliability of such instruments is often inadequate thereby affecting the validity of scores and research findings. With the increasing needs to proffer solutions to the emerging challenges and complex issues in the construction industry through empirical evidences, a clear template for questionnaire development and implementation for researchers in construction management related disciplines becomes imperative. This study therefore seeks to fill this gap by exploring various issues in questionnaire design in construction management studies with the view to broaden the understanding of research students and professionals in the built environment on the subject. The objectives of the study were to: broaden the knowledge of researchers on key issues on questionnaire development and validation and provide a step-by-step guide for designing valid questionnaires for researchers in construction management. The paper presents the process through which the questionnaire for a doctoral study on Managing Risks in Public Private Partnership Housing Projects in Abuja, Nigeria was designed.

\section{LITERATURE REVIEW}

In most academic researches, especially humanities and built environment related fields such as construction management, opinions of experts are very essential. Researchers are expected to elicit information from respondents relating to the identified research variables. In both quantitative and qualitative studies, researchers pose specific and relevant questions to the respondents in order to obtain the needed information which serve as data for the study. These set of questions are referred as the questionnaire. According to Akanoh (2016), questionnaire is a set of questions written by a researcher to gather information from respondents requiring such responses in printed forms which is further analysed in order to answer pre-set research questions; when properly constructed and responsibly administered, questionnaire becomes a vital instrument for generalising research findings about a specific group, people or entire population (Roopa and Satya, 2012).

There basically three forms of questionnaire applicable in the field of construction management. These include the structured, semi-structured and unstructured questionnaire. The structured questionnaire consists of close-ended questions in which the respondent is given set of option to choose from. Structured questionnaire is used to obtain specific data from wide range of respondents; since respondents are restricted to particular set of data, it is easy to analyse. However, this form of questionnaire does not give room for further comments outside the options stipulated by the researcher; hence it limits the researcher's experience to the options thereby depriving the study benefiting from the rich knowledge of the respondent. These forms of questions are mostly used in quantitative studies. Unstructured questionnaires on the other hand consist of open-ended questions requiring the respondent to put down their opinions relating to the subject of study. This form of questionnaire is used to collect information that can be observed and recorded but are not numerical in nature (Ndukwu, 2020). The respondents are given the liberty to bring in their wealth of experience which makes the research finding as robust as possible. One shortcoming of the unstructured questionnaire borders on its analysis. Since respondents are not restricted on the information to be provided, it generates numerous themes that it becomes difficult to manage during the analysis stage. Unstructured questionnaire is often adopted in qualitative research. In between these extreme forms lies the semi-structured questionnaire which combines the two forms of questions earlier discussed; while the respondents are restricted to specific options in some questions, they are required to put down their experience in others. This form of questionnaires are often adopted in mixed researches such as case studies where they could either be explanatory, descriptive or both. By adopting both forms of questions, this type of questionnaire shares in the advantages and disadvantages of both. 
As a research instrument, questionnaires are good for gathering data about abstract ideas or concepts that are otherwise difficult to quantify such as opinions, attitudes and beliefs (Artino, La Rochelle, Dezee and Gehlback, 2014). It has been stressed that, a well designed and considered questionnaire be the difference between success and failure (Ndukwu, 2020). Consequently, quality and standard of a questionnaire is instrumental to the success of a study. It is therefore imperative, that adequate attention is given to questionnaire design; the type of questions, structure, and sequence as well as the difficulty level of the questions in order to boost the success of the study.

\section{METHODOLOGICAL CONSIDERATION FOR DEVELOPING QUESTIONNAIRE IN CONSTRUCTION MANAGEMENT}

Good questionnaire design is crucial in generating data conducive to the goals of a research (Sarantakos, 2005). Questionnaire design is a multistage process that requires attention to many details at once. The process is complex and complicated (Song and Son, 2015) because surveys can ask about topics in varying degrees of details, questions can be ask in different ways, and questions asked previously in a survey study may influence how people respond to subsequent questions. Regardless of the complexity, it is possible to come up with an effective means of collecting data that will answer the unique predetermined research questions by taking a step-by-step approach to questionnaire development. Questionnaire format, sequence and wording, the inclusion of classification, behavioural, Knowledge and perception questions, and question length and output, need to be considered to ensure reliability, validity and sustained engagement of the participants (Bird, 2009). Based on existing literature (Radhakrishma, 2007; Artino, et al., 2014, Patel and Joseph, 2016) the process of designing questionnaires can be grouped into four stages: the background stage, conceptualisation stage; design stage and instrument testing and administration stage as shown in Figure 1.

\subsection{Background stage}

This stage is defined by the problem statement of the research which is a function of existing gap in the literature and personal experience of the researcher related to the subject of study. This requires a thorough understanding of the research problem through extant literature search and readings of related texts. A review of related literature helps to ensure the construct definition aligns with related theory and researches in the field, while also helping the researcher identify the items that could be used or adopted for the study (Gehlbach \& Brinkworth, 2011). A well formulated research problem serves as a compass pointing out clearly the direction of the study. It reveals the gap between the ideal and real situation concerning the subject under consideration stating in specific terms what has been done, what is left undone and what needs to be done in order to address the problem under investigation. The information gathered served as guide on the type of study design as well as the instrument to be adopted in collecting data for the study.

The doctoral study was on managing risks in PPP housing projects. Theories have shown that, whenever a party called the principal contracted another called the agent to undertake an assignment on his behalf which ordinarily would have been done by the principal, there is bound to be conflict of interest which breeds risks (Mu, 2008). These risks impact on projects objectives which needs to properly identified and treated for successful PPP housing projects (Ahmed, Ibrahim and Minai, 2018). However, property managers are often ill prepared in adopting formal risks management in construction projects; in addition, project managers rely on experience and intuition to address project risks; approaches which have not been successful given the number of failed PPP housing projects in Abuja, Nigeria (Ng and Loosemore, 2007; Adeleke, et al., 2018). Review of extant literature showed that studies in risks management in PPP are biased towards infrastructure than housing. There was the need to fill this gap by assessing the risk management practices in PPP housing projects, in Abuja. In order to address these issues raised, there was the need to properly identify and describe the risks factors at play in PPP housing projects. A descriptive study requires the experience and inputs of the stakeholders in PPP housing projects such as government officials and other professionals in the built environment. It was therefore necessary to design an instrument that would be used to gather information from the aforementioned stakeholders. 


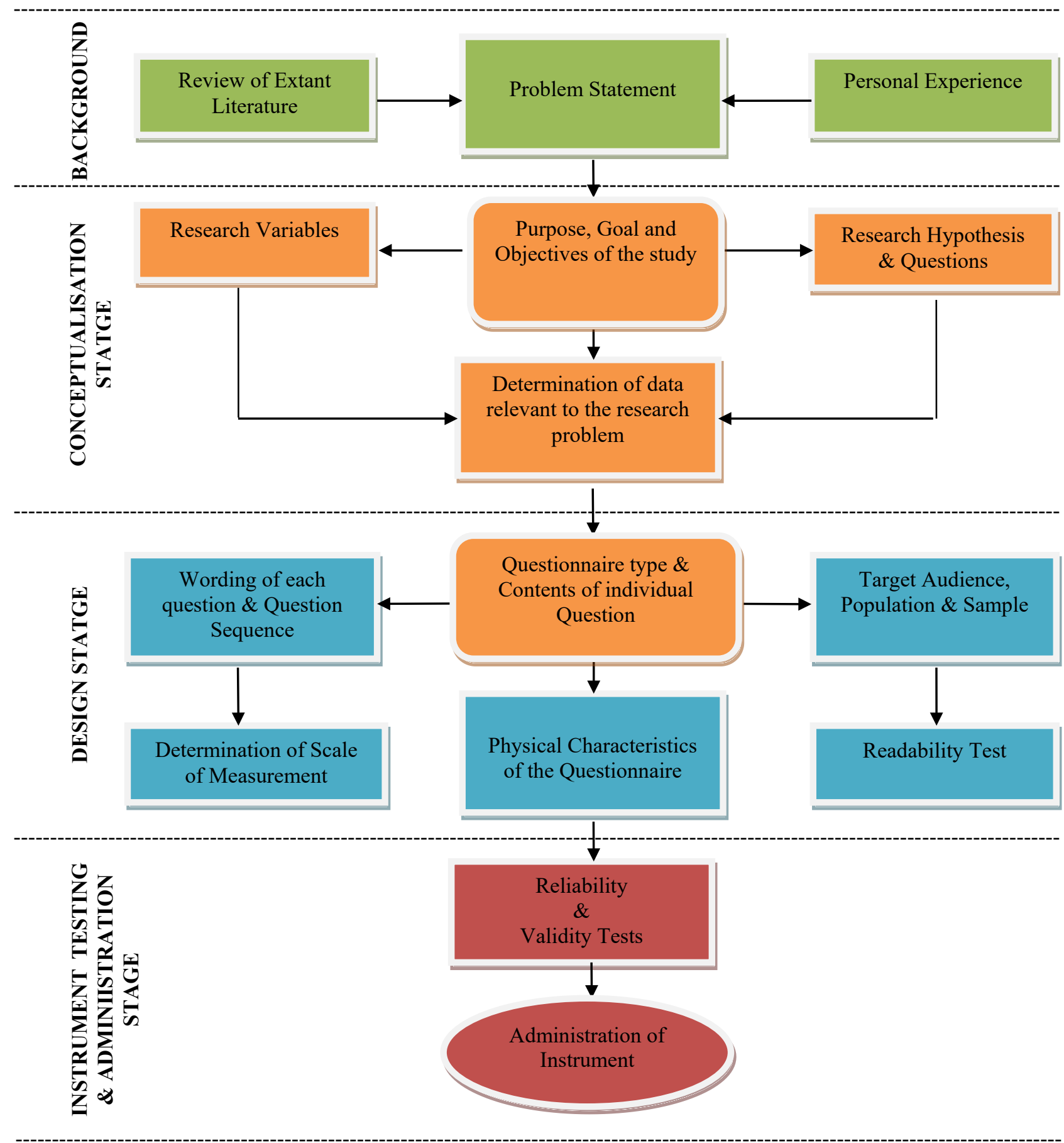

Figure 1: Procedure for Questionnaire Design

\subsection{Conceptualisation stage}

Sequel to developing a thorough understanding of the research is the formulation of research purpose, goal and objectives. In this stage, content (from literature/theoretical framework) is transformed into statements or questions; in addition, a link among the objectives of the study and their translation into content is established (Radhakrishna, 2007). The questions that the research needs to address must be articulated and the hypotheses around which the questionnaire is to be designed must be formulated at this point. Based on the research questions, objectives and hypotheses, the researcher indicates whether the questionnaire is measuring attitudes, perceptions, opinions, bahviour change etc. which determine the types of variables to be used in the study. These variables help the researcher in deciding on the data that needs to be collected from the respondents (Fogli and Herkenhoff, 2018). 
The study, for which the questionnaire was designed, focused on the perceptions of stakeholders on managing risks in PPP housing projects. Consequently, the types of risks associated with PPP housing needed to be identified, the impacts of those risks on achieving project objectives had to be assessed, the strategies for preventing and mitigating risks in PPP housing projects were evaluated and the drivers and barriers for adopting risk management in PPP housing projects were also examined. The study had to ascertain whether significant variations exist among stakeholders in the risks associated with PPP housing projects, impact of risks on project objectives, measures adopted in preventing and mitigating risks, and drivers and barriers to effective implementation of risk management in PPP housing projects in the study area. These information were useful in identifying both the dependent and independent variables needed to be considered in formulating the research hypotheses and designing the questionnaire for the study. Risk factors associated with PPP housing, techniques for risk identification and estimation, impact of risks on project objectives, measures for preventing and mitigating risks, drivers and barriers to implementing risk management in PPP housing were the identified dependent variables while project cost, quality, time, safety, environmental sustainability, satisfaction of contracting parties and ability of target group to access housing units were the dependent variables.

Following the determination of the variables, formulation of research questions and hypotheses, data were obtained on the forms of PPP models used in procuring housing projects, the roles of parties in those projects, risk allocation pattern among contracting parties, political support, availability of market for the housing units, the level of satisfaction of contracting parties, the probability of risk factor occurring and their likely impact on the housing projects, the frequency of usage of risk response measures among others. These data were used in formulating the questions in the next stage of the questionnaire design. Although there is no universally accepted standard on the number of questions to address a research objective, it is required that adequate questions should be asked to cover each objective of the study.

\subsection{Design stage}

This stage focus on writing questions, selection of appropriate scales of measurement, the questionnaire layout, format, question ordering and proposed data analysis (Radhakrishna, 2007). In designing questionnaires, the overarching goals is to develop a set of items that every respondent will interpret the same way, respond to accurately and be willing and motivated to answer (Artino, Rochelle, Dezee, and Gehlbach, 2014). This is achievable by paying careful attention to the question types and content of individual questions, the target audience, wordings of the questions and question sequence. These elements were considered and observed in designing the questionnaire for the doctoral study on managing risks in PPP housing projects in Abuja, Nigeria as explained in this section.

\subsubsection{Question type}

The type of questions to be adopted in designing a questionnaire will depend on whether the researcher wishes to collect qualitative information for the purposes of better understanding or the generation of hypotheses on a subject or quantitative information to test specific hypotheses that have previously been generated (Fogli and Herkenhoof, 2018). There are basically two forms of questions: The open-ended and the closed-ended questions. In between these extreme categories lies the semi-structured type. A research may require the use quantitative and quantitative data necessitating the use of both types of questions in which case it is referred to as a mixed design. Qualitative information could be obtained using open-ended questions while quantitative data are gathered using closed-ended questions. In open-ended questions, no answers are suggested; the respondents are required to reply to the questions in their own words; however, in the closed-ended questions, respondents are given a list of predetermined responses from which to choose their answers (West, 2019).

The Doctoral thesis which was on risk management in PPP housing projects set out to describe the risk factors associated with such projects and to explain their causes and impact on the project objects. Consequently, the research questions were the"what' and "how types suggesting the use of both quantitative and qualitative data. The qualitative data were obtained through interview while the quantitative information were obtained through questionnaire. The study adopted the close-ended questionnaire for ease of analyses and reliability in describing the risk factors prevalent in PPP housing projects in the study area. Questions were provided with options from which the respondents were required to choose from thereby simplifying their participation. 


\subsubsection{Target audience/readability}

The respondents from which the data is collected are critical in designing questionnaires; hence the population about which the researcher generalises the research findings must be defined; the sample frame has to be determined and the demography of the respondents such as age, education, years of experience among others must be taken into consideration to give a fair idea of those supplying information which is key in establishing reliability of research findings (Fogli and Herkenhoff, 2018). Familiarity with the research environment or subgroup of population/respondents enhances the response rate from the questionnaire (Etikan and Bala, 2017). National Oceanic and Atmospheric Administration (2015) stressed that when developing a survey questionnaire, the researcher should consider the level of knowledge the respondents posses about the topic; this will be helpful in constructing questions to accommodate a broad range of respondents and will aid in interpretation of the study findings. Malhotra (2006) stressed that, questionnaires that fail to keep in mind the characteristics of the respondents, particularly their educational background and experience in the subject of study lead to high incidence of uncertain response. In order to increase the response rate and reliability of the instrument, Artino et al., (2014) suggested that questions should be clear and unambiguous using the vocabulary of the target population.

PPP is contractual arrangement between the public entity and private sector; and risk is a contemporary phenomenon which must be studied in context specific without been separated from the environment it occurs. Risk management requires experience accumulated over time from participation in project management. Consequently, the targeted respondents were government officials in housing related departments, contractors, consultants and sponsors with the requisite experience in PPP housing projects and risk Management. Only respondents with a minimum of Higher National Diploma in construction related discipline with over 10 years experience were considered for the study. In formulating the questions, simple language were used to ensure clarity with the view to improving the response rate and reliability of the instrument.

\subsubsection{Wording and sequence of questions/scale of measurement}

The choice of words and phrases in questionnaire are critical in expressing the meaning and intent of the question to the respondents and ensuring that all respondents interpret the question the same way. Poor worded questions can confuse or mislead respondents, leading to response error and in extreme cases refusal to answer those questions or items (Malhotra, 2006). It has been reported that small wording differences can substantially affect the answers people provide; hence it is important to ask questions that are clear and specific and that each respondent will be able to answer (Pew Research Center, 2019). In wording, the practical questions to be considered include if the questions are sufficient to generate the required information, whether the respondent can answer the question correctly, whether there are any external events that might bias response to the question, whether the words used have the same meaning to all respondents, whether any of the words or phrases is loaded or leading in any way, will the question be understood by the type of respondents, is there any ambiguity in the questions, are any words or phrases vague, and whether any of the questions is too personal or of a potentially embarrassing nature (Fogli and Herkenhoff, 2018).

In writing the questions, researchers should avoid technical terms and jargon, avoid vague or imprecise terms, must define things very specifically, avoid complex sentences, avoid negative/double negative questions, avoid double-barrel questions, start with interesting questions and also avoid questions using leading, emotional or evocative language among others (Lee, 2006; Harrison, 2007; Akanoh, 2016). Construct survey questions must be as simply as possible; the vocabulary and sentence structure should maximise the understanding of what is being asked because the greater a respondent understands what is being asked, the greater the chance that a confident response will be made (National Oceaninc and Atmospheric Administration, 2015). Once the survey questions are developed, particular attention should be paid to how they are ordered in the questionnaire. The placement of a question can have a greater impact on the result than the particular choice of words used in the question. The principal requirement of questionnaire format is that the questions are sequenced in a logical order, allowing a smooth transition from one topic to the next (Sarantakos, 2005).

In order to achieve simplicity of wording and the desired sequence in the doctoral questionnaire, 9 academic staff who were experts in survey design were selected to participate in the content validation of the draft instrument. This was in line with the submission of Magee, Richards, Byars and Artno (2013) that the adequate number required for content validity of a questionnaire is between 6-12 experts. The experts identified 5 items that were irrelevant to the study which were eliminated from the instrument; 3 relevant items omitted were later included in the final draft. For instance, financing options stood out in the draft which the experts observed that it was needless since the study was not on financing PPP. On the other hand, techniques for risk identification, risk 
response measures and parties responsible for risk analysis were omitted which the experts felt they were relevant to the study and needed to be included in the instrument. Furthermore, the experts identified items that were difficult to interpret; hence those items were revised and simplified in accordance with the suggestions of the experts. The questions were ordered in line with the study objectives; question relating risk identification were placed first; those relating to impact of risks on project objectives came next followed by items on measures for preventing and mitigating risks in PPP housing projects while questions on the drivers and barriers to the implementation of risk management were placed at the concluding part of the instrument.

\subsubsection{Physical characteristics of the questionnaire}

The physical appearance of a questionnaire can have a significant effect upon both the quantity and quality of data obtained. The quantity of data is a function of the response rate. Ill-designed questionnaires can give an impression of complexity, medium and too big a time commitment. Data quality can also be affected by the physical appearance of the questionnaire with unnecessarily confusing layouts making it more difficult for interviewers, or respondents in the case of self-completion questionnaires, to complete this task accurately. Moran (1990) posited that, the appearance of the questionnaire influences respondents' decision to either participate in the research or not. The appearance and arrangement of the questionnaire should be clear, neat, and easy to follow. In developing a questionnaire, paying attention to a few basic details can have a disproportionately advantageous impact on the data obtained through a questionnaire. In general, it is best for a questionnaire to be as short as possible. A long questionnaire is open to the dangers of boredom on the part of the respondent resulting to poorly considered and hurried answers; however, other criteria for format and layout should not be sacrificed and the length of the questionnaire should reflect the purpose of the analysis and evaluation (Lee, 2006).

In order to improve the participation by the respondents, much attention was paid to the structure of the questionnaire. The instrument was divided into three sections; the first focused on the general information of the respondents, the second section considered information of PPP housing projects while the third section focused on risk management. The instructions were separated from the questions as suggested by Lee (2006). Major Sections were rendered in capitals, questions and options were in lower cases with the various options placed one underneath the other. The graphics were of high-quality with space between questions and good layout in order to improve accuracy, completeness and to help the questionnaire flow and gets higher response.

\subsection{Instrument testing and administration stage}

Even after the researcher has proceeded along the lines suggested, the draft questionnaire is a product evolved by one or two minds only. Until it has actually been used in interviews and with respondents, it is impossible to say whether it is going to achieve the desired results. Before administering the questionnaire therefore, it is important to learn whether the instrument works satisfactorily or has any major problem (Needman and Vaske, 2008). For this reason, it is necessary to pretest and pilot test the questionnaire before it is used in a full-scale survey, to identify any mistakes that need correcting.

The purpose of pre-testing the questionnaire is to determine whether the questions are understood by all classes of respondents, whether respondents are interpreting the questions as intended, whether the questions as they are worded will achieve the desired results, whether the questions have been placed in the best order, whether the order of the questions may influence responses, whether additional or specifying questions are needed or whether some questions should be eliminated and whether the instructions to interviewers are adequate (Fogli and Herkenhoff, 2018; Pew Research Center, 2019). The pretest should be administered to a small group of individuals who are as similar as possible to those being sampled. Pretest allows the researcher to gauge the types of responses being received for each question and it serves as a means of quality assurance for grammar, sentence structure, and clarity (National Oceaninc and Atmospheric Administration, 2015). The questionnaire was pretested through cognitive survey in which 8 participants drawn from the targeted population were invited in line with the submission of Magee et al., (2013). The participants were engaged in a face-to-face interview, each participant was asked to read each item aloud and explain her/her understanding of it. The essence was to verify whether each respondent interpret the items as the researcher intended. Following the pretesting, items that were adjudged to be ambiguous and fail to evoke the desired cognitive response were recast in order to improve clarity of the instrument before taking it out for pilot study.

Sequel to pretest is the pilot test which the researcher uses to evaluate how a sample of people from the survey population responds to the questionnaire; pilot testing is conducted on a larger number of people so that the potential differences within and across groups in the population can be analysed (Pew Research Center, 2019). The 
essence of the pilot testing is basically to determine the reliability and validity of the instrument. Reliability refers to the consistency of a question; the probability of obtaining the same results if the question is duplicated (Bird, 2009). Validity expresses the degree to which an instrument measures what it purports to measure (Bolarinwa, 2016). Validity tests are categorised into internal and external validities. Internal validity refers to how accurately the measures obtained from the research was actually quantifying what it was designed to measure whereas external validity refers to how accurately the measures obtained from the study sample described the reference population from which the study sample was drawn (Last, 2001; Rothman, Greenland and Lash, 2008). The doctoral questionnaire was pilot tested on 30 respondents, drawn from the targeted respondents including the academics and housing consumers. The items considered in the validity and reliability tests were clarity of the questions, ability of the instrument to address the construct and answer the research questions, the structure of the questionnaire, and order of questions. These items were set on scale of 1-5; 1 indicating "Not agreed" and 5 "strongly agreed. The mean score and standard deviations were computed. The Cronbach Alpha value of 0.81 was obtained which indicated high correlation among the items considered which suggested acceptability of the instrument.

Following a successful pilot test is the mode of administering the instrument. Questionnaire can be administered through mail, by telephone, in-person or online. However in deciding which of approach to use, the researcher should consider the cost of contacting the study participants and data collection, the literacy level of the participants, response rate requirements, respondent burden and convenience, the complexity of the information being sought for and the mix of open-ended and close-ended questions, nature of the population, availability of resources, sample size and distribution, and time constraint (de Vaus, 2002; West, 2019). In order to improve the effectiveness of using questionnaire Lee (2006) stressed that, during administering the instrument, researchers should explain the purpose of the questionnaire, have a neutral/third party administer the questionnaire, provide a copy of the questionnaire in advance, consider quantifying program ratings for comparisons and provide enough time for completing the questionnaire.

Riding from a successful pilot study, the questionnaire was administered on the target respondent inperson with the help of research assistants. Research fellows were recruited and trained for that purpose. The responsibility of the research assistants were to identify the targeted respondents, determine their suitability for participation based on the predetermined criteria, deliver the instrument to them and retrieve same when they are duly completed by the respondents. Ample time was given to the participants to respond to the questions. The questionnaires were collected and collated based on classes of respondents for ease of analysis. For instance, Kruskal Walis Test was used to determine whether there is no significant variation among stakeholders in the risk factors associated with PPP housing projects. This method of data analysis requires that, there must be more than two groups of respondents which necessitated the sorting of the instrument according to the class of respondents. The collated questionnaire was analysed using the methods specified in the study and the results was communicated to the predetermined audience.

\section{CONCLUSION}

Despite popular use of questionnaires for acquiring data in construction management related studies, the techniques employed for their development and implementation have been a relatively neglected topic. Consequently, development of questionnaire remains a challenging issue among postgraduate students in the field of construction management. This paper offers a template for researchers conducting investigations in the field construction management focusing on managing risks in PPP housing projects. The article highlights the basic steps and techniques used in developing and implementing questionnaires and it emphasises the need for researchers to be meticulous by providing enough details on important methodological features. The various stages and processes of developing questionnaire were considered and detailed strategies adopted in designing the instrument for the doctoral research were discussed. These stages would simply the task of designing questionnaire among construction management students and supervisors. Results of validity and reliability tests conducted on certain aspects of the questionnaire indicated that the instrument can be relied upon to generate acceptable data for scientific research. It is expected that if the stages and design guidelines presented in this paper are followed, it will lead to the design of a questionnaire that would lead to the collection of valid, reliable and robust data for postgraduate researches in construction management. 


\section{REFERENCES}

Adeleke, A. O., Bahaudin, A. Y., Kamaruddeen, A. M., Bamgbage, J. A., Salimon, M. G., Waris, M. and SaooShian, S. (2018). The Influence of Organisational External Factors on Cosntruction Risk Management among Nigerian Construction Companies. Safety and Health at Work, 9, 115-124.

Ahmad, U., Ibrahim, Y., and Minai, M. S. (2018). Malaysian Public Private Partnership: Risk Management in Build, Lease, Maintain and Transfer Projects. Cogent Business ans Management, 5, 1-25.

Akanoh, C. (2016). How to Write and Characteristics of a Good Questionnaire. Afribary. Available at www.https//howtowriteandcharacteristicsofagoodquestionnaire. Retrieved on $30^{\text {th }}$ August, 2019.

Artino, A. R., Gehlbach, H. and Durning, S. J. (2011). Avoiding Five Common Pitfalls of Survey Design Academic Medicine, 86 (1), 1327-1337

Artino, A. R., La Rochelle, J. S., Dezee, K. J. and Gehlbach, H. (2014). Developing Questionnaire for Educational Research. Medical Teacher, 36(6); 463-474.

Bird, D. K. (2009). The Use of Questionnaires for Acquiring Information on Public Perception of Natural Hazard and Risk Mitigation - a Review of Current Knowledge and Practice. System Sciences, 9, 1307-1325.

Bolarinwa, O. A. (2016). Principles and Methods of Validity and Reliability Testing of Questionnaires Used in Social and Health Science Researches. Nigeria Postgraduate Medical Journal, 22, 195-201.

De Vaus, D. A. (2002). Surveys in Social Research (5 $5^{\text {th }}$ Ed). Crows Nest, Australia: Allen \& Unwin.

Etikan, I. and Bala, K. (2017). Developing Questionnaire Base on Selection and Design. Biometrics and Biostatistics International Journal, 5(6); 219 - 221.

Fogli, J. and Herkenhoff, L. (2018). Conducting Survey Research: A Practical Guide. New York: Business Experts Press.

Gehlbach, H. and Brinkworth, M. E. (2011). Measure Twice, Cut Down Error: A process for Enhancing the Validity of Survey Scale. Rev. Gen. Psychol. 15: 380-387.

Harrison, C. (2007). Tip Sheet on Question Wording: Program on Survey Research. Harvard University. Available at https//psr.iq.harvard.edu. Retrieved on $22^{\text {nd }}$ November, 2019.

Last, J. M. (2001). A Dictionary of Epidemiology (4 ${ }^{\text {th }}$ ed). New York: Oxford University Press

Lee, S. H. (2006). Constructing Effective Questionnaires. In E. J. Keeps, H. D. Stolovitch and J. Pershin. Handbook of Human Performance Technology ( $3^{\text {rd }}$ Ed). Hoboken, NJ: Pfeiffer Wiley.

Malhotra, N. (2006). Questionnaire Design and Scale Development. Uses, Misuses and Future Advances. Available at https://www.researchgate.net/publication/266864633. Retrieved on $\quad 18.08 .2019$.

Mathers, N., Fox, N. \& Hunn, A. (2009). The NIHR Research Design Service for East Midlands: Surveys and Questionnaires. National Institute for Health Research.

Mu, R. (2008). Public Private Partnerships and the Management of Expressways in China: An Agency Theory Approach. Engineering and Analysis. The Neitherlands: Delft University of Technology.

National Oceanic and Atmospheric Administration (2015). Introduction to Survey Design and Delivery. USA: United State Department of Commerce.

Ndukwu, D. (2020). Questionnaire: Types, Definition, Examples and How to Design your Questionnaires. KyLeads. Retrieved from www.Kyleads.com/blog/questionnaires 29.07.2020 
Needman and Vaske, J. J. (2008). Survey Implementation and Sampling. In J. J. Vaske, Survey Research and Analysis: Application in Human Dimension of Natural Resources. State College, PA: $\quad$ Venture Publishing.

Neuman, W. L. (1997). Social Research Methods: Qualitative and Quantitative Approaches (3 ${ }^{\text {rd }}$ Ed). Boston: Allyn \& Bacon.

$\mathrm{Ng}$, A. and Lossemore, M. (2007). Risk Allocation in the Provision of Public Infrastructure. International Journal of Project Management. 25(1), 66-76.

Patel, H. R. and Joseph, J. M. (2016) Questionnaire Designing Process: A Review. Journal of Clinical Trials.6 (2); $2-7$

Pew Research Center (2019). Questionnaire Design. Washington DC: USA

Radhakrishna, R. B. (2007). Tips for Developing and Testing Questionnires/Instruments. Journal of Extension, $45(1) ; 1-4$.

Radhakrishna, R. B., Francisco, C. L. and Baggett, C. D. (2003). An Analysis of Research Design Used in Agricultural and Extension Education. Proceedings of the $30^{\text {th }}$ National Agricultural Education Research Conference, 528-541.

Rothman, K. J., Greenland, S. and Lash, T. L (2008). Modern Epidemiology. Philadelphia, USA: Lippincott William and Wilkins.

Roopa, S. and Satya, R. M. (2012). Questionnaire Design for Survey. Journal of Indian Orthodontic Survey, 46(4); 37- 41

Root, D. and Blismas, N. G. (2003). Increasing Questionnaire Responses from Industry: Practices Surrounding the Use of Postal Questionnaires. In Grenwood, D. J. (Ed), Proceedings of $19^{\text {th }}$ Annual ARCOM Conference, 3-5 September, University of Brighton. Association of Researchers in Construction Management, 2 (1); 623-31

Sarantakos, S. (2006). Social Research (2 ${ }^{\text {nd }}$ Ed.). Hampshire: Palgrave Macmillan.

Seymour, D. A. and Rooke, J. (1995). The Culture of the Industry and the Culture of Research. Construction Management and Economics, 13(16); 511-523

Song, Y. and Son, Y. J. (2015). Methodological Issues in Questionnaire Design. Journal of Korean Academy of Nursing, 45(3); 323-328

West, J. (2019). Data Collection. New York: Child Care and Early Education Research Connections, 1; 1-55

Wong, K. L., Ong, S. F. and Kuek, T. Y. (2012). Constructing a Survey Questionnaire to Collect Data on Service Quality of Business Academics. European Journal of Social Sciences, 29, 209-

Yaddanapudi, S. Y. and Yaddanapudi, L. N. (2019). How to Design a Questionnaire. Indian Journal of Anaesthesia, 63(5); 335-337.

Yin, R. K. (2009). Case Study Research - Design and Methods (4 ${ }^{\text {th }}$ Ed). CA: Sage Publications Inc. 